\title{
CONTRASTES E SIMILARIDADES: um olhar de gênero sobre Cursos de Engenharias e Licenciaturas da UTFPR e da UFBA ${ }^{1}$
}

Lindamir Salete Casagrande lindasc@utfpr.edu.br Universidade Tecnológica Federal do Paraná (UTFPR), Curitiba, Paraná, Brasil.

\section{Ângela Maria Freire de Lima e} Souza

freiredelimaesouza@gmail.com Universidade Federal da Bahia (UFBA), Salvador, Bahia, Brasil

\begin{abstract}
RESUMO
O objetivo deste artigo é apresentar dados relativos à participação masculina e feminina nos cursos de Engenharia Civil e Mecânica e Licenciaturas em Letras e Matemática da UTFPR e da UFBA. Para este estudo, utilizaremos o método quantitativo com base em informações obtidas junto às duas instituições. Os resultados aqui apresentados integram a primeira etapa da pesquisa para a realização do estágio de pós-doutorado junto ao Programa de PósGraduação em Estudos sobre Mulheres, Gênero e Feminismo - PPGNEIM da Universidade Federal da Bahia - UFBA, cujo objetivo é analisar as engenharias e licenciaturas da UTFPR e UFBA sob a perspectiva de gênero. $O$ estudo compreende duas etapas: a primeira, de cunho quantitativo, visa construir o panorama desta participação nos referidos cursos e tem os resultados aqui apresentados. A segunda etapa, de enfoque qualitativo, pretende conhecer os motivos pelos quais homens e mulheres optam por um ou outro curso, bem como as dificuldades e facilidades enfrentadas por eles e elas para se manter nos cursos escolhidos, considerando seus respectivos contextos socioculturais. Os dados apontam que as mulheres são a minoria nas Engenharias, de modo especial na Engenharia Mecânica onde os números raramente atingem $15 \%$. No que tange as licenciaturas, elas são maioria absoluta em Letras, porém em Matemática os números oscilam bastante e ficam próximos. É importante demarcar que diferenças regionais e/ou culturais parecem não alterar a distribuição desigual de homens e mulheres nos cursos analisados, em duas instituições contrastantes em muitos aspectos. Os resultados aqui apresentados indicam a relevância da realização da segunda etapa da pesquisa.
\end{abstract}

PALAVRAS-CHAVE: Relações de Gênero. Engenharias. Licenciaturas. UTFPR. UFBA. 


\section{INTRODUÇÃO}

Este artigo tem por objetivo apresentar os dados quantitativos relativos a participação masculina e feminina nas licenciaturas e engenharias da UTFPR e da UFBA. Estes dados correspondem a primeira etapa da pesquisa para a realização do pós-doutorado junto ao Programa de Pós-Graduação Interdisciplinar em Mulheres, Gênero e Feminismo - PPGNEIM da Universidade Federal da Bahia - UFBA cujo objetivo é analisar os cursos de Engenharia Mecânica e Civil e Licenciatura em Letras e Matemática da UTFPR e UFBA sob a perspectiva de gênero. Para tal tornouse necessário construir o panorama sobre a presença feminina e masculina nos cursos de engenharia (Mecânica e Civil) e nas licenciaturas (Letras e Matemática) das duas universidades.

A análise se deu com base na teoria de gênero, considerando o gênero como social e culturalmente construído, representa e estabelece relação de poder (SCOTT, 1995 e COSTA, 1994) e permeia todos os setores da sociedade, estando, desta forma, presente no meio universitário também.

Estudos (CARVALHO; CASAGRANDE, 2011 e 2009; CARVALHO, 2008; CASAGRANDE et al, 2004; LOMBARDI, 2006; CABRAL, 2005; dentre outros) mostram que as mulheres são minoria nas carreiras científicas e tecnológicas, não só no Brasil como também em outros países. Esta realidade também se aplica a UTFPR e a UFBA que estão inseridas na sociedade atual. Acredita-se que existam múltiplos fatores que contribuem para o baixo índice de participação feminina nos cursos de engenharia.

Segundo Marta González Garcia e Eulália Pérez Sedeño (2006, p. 46), a suposta falta de habilidade Matemática e espacial "explicaria o escasso número de mulheres nas engenharias e arquitetura, profissões que requerem habilidade para as Matemáticas e as relações espaciais". Entretanto, esta não pode ser pensada como a única causa para tal fato. Léa Velho (2006, p. xiv) argumenta que a socialização diferenciada de meninos e meninas é fundamental para o desenvolvimento das habilidades e no decorrer deste processo "as mulheres são ensinadas a procurar ajuda e a ajudar e não a serem autoconfiantes ou a funcionar autônoma e competitivamente como os garotos". O prazer, a atração e o gosto pelas engenharias pode ser desenvolvido igualmente em meninas e meninos desde que sejam oferecidos a todos e todas os mesmos estímulos.

Este fato ficou evidente no caso da iraniana Maryam Mirzakhani, primeira mulher a ganhar a medalha Fields ${ }^{2}$. O site www.terra.com.br (2014) relata que um professor do ensino médio "disse que ela não tinha nenhum talento especial para a área. 'É tão importante o que os outros veem em você', diz. 'Eu perdi meu interesse na Matemática.' No segundo ano, contudo, ela teve outro professor que a incentivou e ela se tornou a 'estrela da turma'”. Este é um caso emblemático e que evidencia a importância do estímulo e da valorização das habilidades tanto de homens quanto de mulheres.

Também será parte das análises apresentadas nesta comunicação os números relativos a participação masculina e feminina nas licenciaturas. Para tal, escolhemos as licenciaturas em letras, reduto feminino e em Matemática, supostamente masculino. O magistério tem se constituído ao longo dos anos como um campo com predominância de mulheres. Sendo assim, cabe analisar se 
estes cursos oferecidos pela UTFPR e pela UFBA mantêm esta tradição de formar predominantemente professoras.

\section{AS ENGENHARIAS SOB A PERSPECTIVA DE GÊNERO}

As engenharias são ofertadas em todos os campi da UTFPR. A instituição é tradicional na oferta de engenharias sendo uma das mais reconhecidas no cenário estadual e nacional, quiçá internacional. A gama de Engenharias ofertadas pela instituição é diversa com 21 cursos ofertados nos 12 campi $^{3}$. 0 curso mais frequente é o de Engenharia Mecânica aparecendo em 6 (seis) campi, Engenharia Ambiental e Elétrica vem na sequência com 4 (quatro) campi nos quais elas são ofertadas.

O QUADRO 1 mostra os números de alunos e alunas em cada curso do campus Curitiba no final do ano de 2013. Percebe-se que as mulheres são minoria em todos os cursos, sendo que em Engenharia Industrial de Automação apenas 10,5 \% do total de estudantes do curso são mulheres e Engenharia da Computação onde elas correspondem a apenas $12,1 \%$ do total. Estes números são significativos pois evidenciam que estes são campos que se mantém resistentes a presença feminina. Londa Schiebinger (2001) argumenta que as mulheres lançam olhares para pontos que escapam à visibilidade dos homens. Trazem formas diferentes de se fazer ciência, trazem modos diferentes de se olhar um determinado problema. A reduzida taxa de mulheres nestes cursos dificulta a possibilidade do olhar feminino aparecer no desenvolvimento destes campos do conhecimento.

QUADRO 1 - Estudantes das Engenharias do campus Curitiba da UTFPR por curso e por sexo.

\begin{tabular}{|c|c|c|c|c|c|c|}
\hline \multirow[t]{2}{*}{ Curso de engenharia } & \multicolumn{2}{|c|}{$M$} & \multicolumn{2}{|c|}{$\mathbf{F}$} & \multicolumn{2}{|c|}{$\mathrm{T}$} \\
\hline & $\mathrm{n}$ & $\%$ & $\mathrm{n}$ & $\%$ & $n$ & $\%$ \\
\hline Engenharia da Computação & 290 & 87,9 & 40 & 12,1 & 330 & 100 \\
\hline Engenharia Industrial de Automação & 94 & 89,5 & 11 & 10,5 & 105 & 100 \\
\hline Engenharia da produção Civil & 102 & 67,5 & 49 & 32,5 & 151 & 100 \\
\hline Engenharia Elétrica & 372 & 79,5 & 96 & 20,5 & 468 & 100 \\
\hline Engenharia Eletrônica & 192 & 85,3 & 33 & 14,7 & 225 & 100 \\
\hline Engenharia Industrial Eletrônica & 142 & 86,6 & 22 & 13,4 & 164 & 100 \\
\hline Engenharia Industrial Eletrotécnica & 254 & 87,3 & 37 & 12,7 & 291 & 100 \\
\hline $\begin{array}{l}\text { Engenharia Industrial Mecânica e Engenharia } \\
\text { Mecânica }\end{array}$ & 646 & 85,1 & 113 & 14,9 & 759 & 100 \\
\hline Total & $\underline{2092}$ & 83,9 & 401 & 16,1 & 2493 & 100 \\
\hline
\end{tabular}

Fonte: Registros da Instituição. Elaboração própria.

Legenda: $\mathrm{M}$ - sexo masculino $\mathrm{F}$-Sexo feminino $\mathrm{T}$-total $\mathrm{n}$ - número absoluto \% porcentagem relativa ao número absoluto por sexo sobre o total por curso.

A Engenharia Civil é a que apresenta a maior porcentagem de mulheres chegando a $32,5 \%$ no campus Curitiba, ficando porém, bem abaixo da metade do total de discentes. Ou seja, mesmo na engenharia que se mostra mais atraente para as mulheres elas são minoria. Ao olhar os números relativos a totalidade de estudantes da engenharia a situação é preocupante. No campus Curitiba elas correspondem a apenas $16,1 \%$ do total de discentes.

Como podemos observar no QUADRO 1, nesta pesquisa abordaremos dois cursos com índices bem distintos de participação de mulheres no quadro 
discente, Mecânica com 14,9\% e Civil com 32,5\% de mulheres no seu quadro de alunos/as.

Ao comparar o campus da capital com o total do interior observamos que a porcentagem feminina nas engenharias do interior é significativamente superior à da capital. No interior as mulheres atingem uma porcentagem de $33,2 \%$ enquanto que na capital esta porcentagem corresponde a apenas $16,1 \%$, ou seja, menos da metade. Com base nestes dados percebemos que os cursos de Engenharia da UTFPR tanto em Curitiba quanto no interior permanecem um reduto masculino.

Quando olhamos para os campi do interior, embora na média estas porcentagens aumentem, nas engenharias mais tradicionais o panorama não se modifica muito e ainda piora. Vejamos o caso da Engenharia Mecânica e Industrial Mecânica ${ }^{4}$ nos diversos campi nos quais os cursos são ofertados (QUADRO 2). Pode-se perceber que as porcentagens femininas caem. Ou seja, a escassez do olhar e pensamento feminino é ainda mais perceptível em campi menores, sendo que em Londrina, onde funciona somente o primeiro semestre, pois o campus e o curso são novos, apenas 4 (quatro) mulheres encontram-se matriculadas neste curso perfazendo $9,5 \%$ do total de discentes. Estes dados mostram que estas são características dos cursos e não somente da UTFPR campus Curitiba que traz em seu bojo a tradição de acolher predominantemente homens em seu corpo discente.

QUADRO 2 - Estudantes das Engenharias Mecânica e Industrial Mecânica da UTFPR por campus e por sexo

\begin{tabular}{|c|c|c|c|c|c|c|}
\hline \multirow[t]{2}{*}{ Campus } & \multicolumn{2}{|c|}{ M } & \multicolumn{2}{|c|}{$\mathbf{F}$} & \multicolumn{2}{|c|}{$T$} \\
\hline & $\mathrm{n}$ & $\%$ & $\mathrm{n}$ & $\%$ & $\mathrm{n}$ & $\%$ \\
\hline Curitiba & 646 & 85,1 & 113 & 14,9 & 759 & 100 \\
\hline Cornélio Procópio & 269 & 86,8 & 41 & 13,2 & 310 & 100 \\
\hline Guarapuava & 182 & 86,3 & 29 & 13,7 & 211 & 100 \\
\hline Pato Branco & 314 & 86,3 & 50 & 13,7 & 364 & 100 \\
\hline Ponta Grossa & 363 & 85,8 & 60 & 14,2 & 423 & 100 \\
\hline Londrina & 38 & 90,5 & 4 & 9,5 & 42 & 100 \\
\hline Total & 1812 & 85,9 & 297 & 14,1 & 2109 & 100 \\
\hline
\end{tabular}

Fonte: Registros da Instituição - Elaboração própria

Legenda: $\mathrm{M}$ - sexo masculino $\mathrm{F}$-Sexo feminino $\mathrm{T}$ - total $\mathrm{n}$ - número absoluto

$\%$ porcentagem relativa ao número absoluto por sexo sobre o total por campus.

Vamos lançar o olhar para o curso de Engenharia Civil e da Produção $\mathrm{Civil}^{5}$, curso este que apresenta a maior porcentagem feminina no campus Curitiba. $\mathrm{O}$ Curso é ofertado em 4 (quatro) campi, sendo 3(três) no interior (QUADRO 3). O campus Pato Branco é o que apresenta a maior porcentagem de mulheres $(48,3 \%)$, entretanto mesmo neste campus elas ainda são minoria. Por outro lado, Campo Mourão é o campus no qual encontramos a menor porcentagem feminina na Engenharia Civil (29,3\%), ou seja, há uma diferença de quase 20 pontos percentuais entre os dados dos dois campi, um localizado no Sudoeste e outro no Centro-Oeste do Estado. No total de estudantes matriculados/as nestes dois cursos em todos os campi elas correspondem a $36,1 \%$, número significativamente superior aos apresentados no QUADRO 1, onde lê-se que as mulheres são $16,1 \%$ do total de estudantes matriculados/as nas engenharias do 
campus Curitiba. Os dados evidenciam que a Engenharia Civil atrai mais mulheres do que áreas como a Mecânica e a Computação.

É importante ressaltar que Pato Branco, mesmo tendo $48,3 \%$ de mulheres na Engenharia Civil, esta porcentagem cai para 23,5\% quando analisamos todas as engenharias ofertadas no campus, ou seja, as demais engenharias neste campus apresentam porcentagens inferiores de participação feminina no quadro discente. A média do campus é quase 10 pontos percentuais inferior à média de todos os campi do interior. É bom salientar que este é o segundo campi da UTFPR em número de matriculados/as nas engenharias.

QUADRO 3 - Estudantes das Engenharias Civil e da Produção Civil da UTFPR por campus e por sexo.

\begin{tabular}{|c|c|c|c|c|c|c|}
\hline \multirow[t]{2}{*}{ Campus } & \multicolumn{2}{|c|}{ M } & \multicolumn{2}{|c|}{$\mathbf{F}$} & \multicolumn{2}{|c|}{$\mathrm{T}$} \\
\hline & $\mathrm{n}$ & $\%$ & $\mathrm{n}$ & $\%$ & $\mathrm{n}$ & $\%$ \\
\hline Curitiba & 102 & 67,5 & 49 & 32,5 & 151 & 100 \\
\hline Campo Mourão & 421 & 71,7 & 166 & 28,3 & 587 & 100 \\
\hline Pato Branco & 194 & 51,7 & 181 & 48,3 & 375 & 100 \\
\hline Toledo & 173 & 61,8 & 107 & 38,2 & 280 & 100 \\
\hline Total & 890 & 63,9 & 503 & 36,1 & 1393 & 100 \\
\hline
\end{tabular}

Fonte: Registros da Instituição - Elaboração própria

Legenda: $\mathrm{M}$ - sexo masculino $\mathrm{F}$-Sexo feminino $\mathrm{T}$-total $\mathrm{n}$ - número absoluto $\%$ porcentagem relativa ao número absoluto por sexo sobre o total por campus.

No que tange aos/às ingressantes nas duas engenharias selecionadas para esta pesquisa no campus Curitiba na década de 2003 a 2012 podemos observar que as mulheres são a minoria em todos os anos e em ambos os cursos. No caso da Engenharia Mecânica a maior porcentagem feminina ocorreu no ano de $2010 \mathrm{com}$ 20,1\% dos/as ingressantes e a menor incidência ocorreu no ano de $2005 \mathrm{com}$ apenas 4,5\%. Pode-se observar que nos últimos 3 anos analisados houve um acréscimo na porcentagem de mulheres que buscaram este curso apontando para uma possibilidade de crescimento no interesse feminino pela área.

Para o curso de Engenharia Civil, embora mais elevadas, as taxas femininas permanecem inferiores às masculinas. A maior incidência também ocorreu no ano de $2010 \mathrm{com} 44,2 \%$ e a menor porcentagem de ingressantes femininas ocorreu no ano anterior (2009) com 30,9\% do total de ingressantes no ano. Quando analisamos os últimos 3 anos observamos uma queda de cerca de 10\% nos índices de participação feminina neste curso.

Lembramos que o SISU foi adotado como forma principal de ingresso na UTFPR no ano de 2010. Este fato fez com que houvesse uma mudança no corpo discente da instituição e pode ter propiciado o maior ingresso feminino nas engenharias, já que foi a partir deste ano que aumentou a porcentagem feminina nos cursos aqui analisados, porém, certamente não foi a única razão para este fenômeno.

Observa-se que os números oscilam bastante de um ano para outro nos dois cursos. Não é possível prever como será o comportamento destes índices nos anos vindouros, porém pode-se inferir que estes cursos se mostram atraentes para as mulheres.

Quando observamos os números relacionados aos/às concluintes nos mesmos cursos, no mesmo campus e na mesma década temos que o panorama 
no curso de Engenharia Mecânica fica ainda pior. O maior índice de formandas

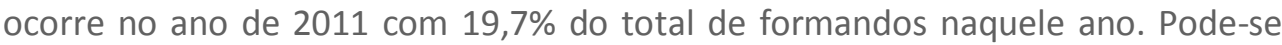
dizer que é um índice alto porém, como o pior índice está no ano anterior no qual nenhuma mulher se formou podemos inferir que as mulheres que não conseguiram concluir seu curso em 2010 somaram com as que concluiriam em

2011 e elevaram a porcentagem feminina dentre os/as formandos/as. Se fizermos a média entre os dois anos ficaremos com números aproximados aos demais anos da pesquisa. Apenas em 3 anos a porcentagem feminina ultrapassou a casa dos dois dígitos, ficando entre 10 e $20 \%$.

Ao compararmos os números de ingressantes e concluintes percebemos que as porcentagens de mulheres concluintes em Engenharia Mecânica na UTFPR campus Curitiba são inferiores às de ingressantes (GRÁFICO 1) na maioria dos anos pesquisados. Este é um indício de que as mulheres têm mais dificuldades para permanecer neste curso. Muitas daquelas que se interessam e conseguem ingressar neles não conseguem permanecer e não concluem o curso. Os motivos para tal fato não são possíveis de determinar com base nestes dados. Para tal seria necessária a realização de pesquisa com estudantes que abandonaram o curso antes da conclusão. Talvez a segunda parte da pesquisa na qual entrevistaremos estudantes dos cursos pesquisados possa indicar algum indicio destes motivos.

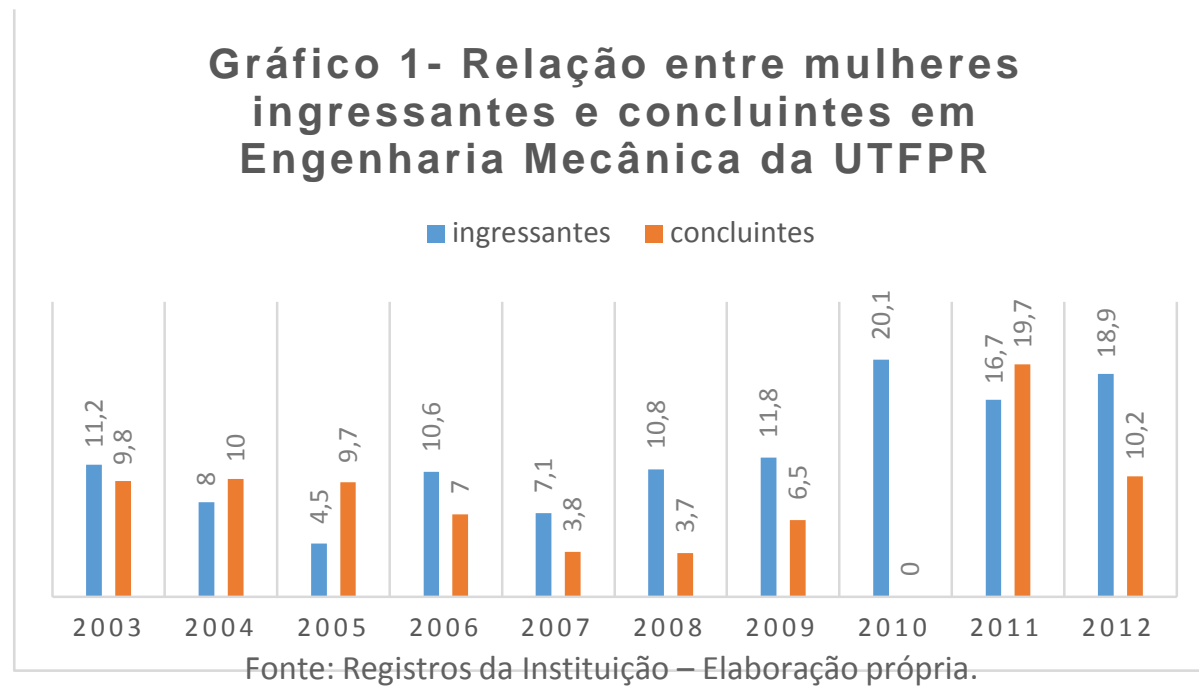

Quando lançamos o olhar para a presença feminina nos cursos de engenharia da UFBA percebemos que o cenário é ainda pior do que o encontrado na UTFPR campus Curitiba. Comparando os dados dos gráficos 1 e 2 percebemos que a porcentagem de ingressantes e concluintes na UFBA são menores do que as encontradas na UTFPR campus Curitiba. Na UTFPR campus Curitiba, no que se refere a engenharia mecânica, a porcentagem de ingressantes variou de 4,5\% (2005) a 20,1\% em 2010. Por outro lado, na UFBA a variação foi de 2,3\% (2004) a 16,7\% (2012). De modo geral, os números relativos ao ingresso de mulheres na UTFPR são superiores aos encontrados na UFBA. Porém, convém destacar que em ambos os casos estes números são extremamente baixos.

No que diz respeito às porcentagens de concluintes observamos que em 4 anos (2004, 2004, 2008 e 2009) da década analisada não houve nenhuma mulher dentre os formandos da UFBA. Na UTFPR campus Curitiba em apenas um ano 
(2010) não ouve formandas porém no ano seguinte a porcentagem de formandas foi de $19,7 \%$ indicando que as mulheres que ficaram retidas em 2010 concluíram o curso em 2011, fato que não ocorreu na UFBA. A UTFPR campus Curitiba apresenta porcentagens de formandas superior aos encontrados na UFBA ao longo da década analisada. Quando comparamos a porcentagem de ingressantes e concluintes, nas duas universidades temos porcentagens menores de mulheres concluintes do que de ingressantes na maioria dos anos.

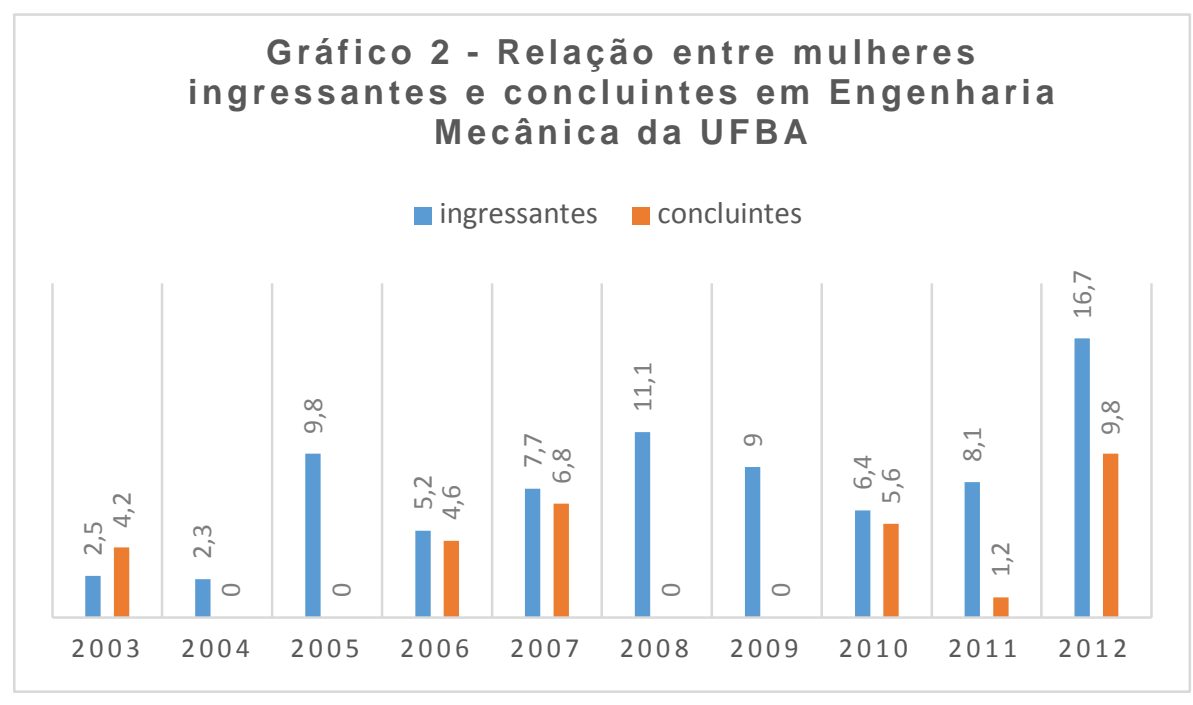

Fonte: Registros da Instituição - Elaboração própria.

No que diz respeito a engenharia Civil da UTFPR campus Curitiba, as porcentagens de mulheres ingressantes e concluintes são próximas e na maioria dos anos analisados a porcentagem de formandas é superior a de ingressantes (GRÁFICO 3).

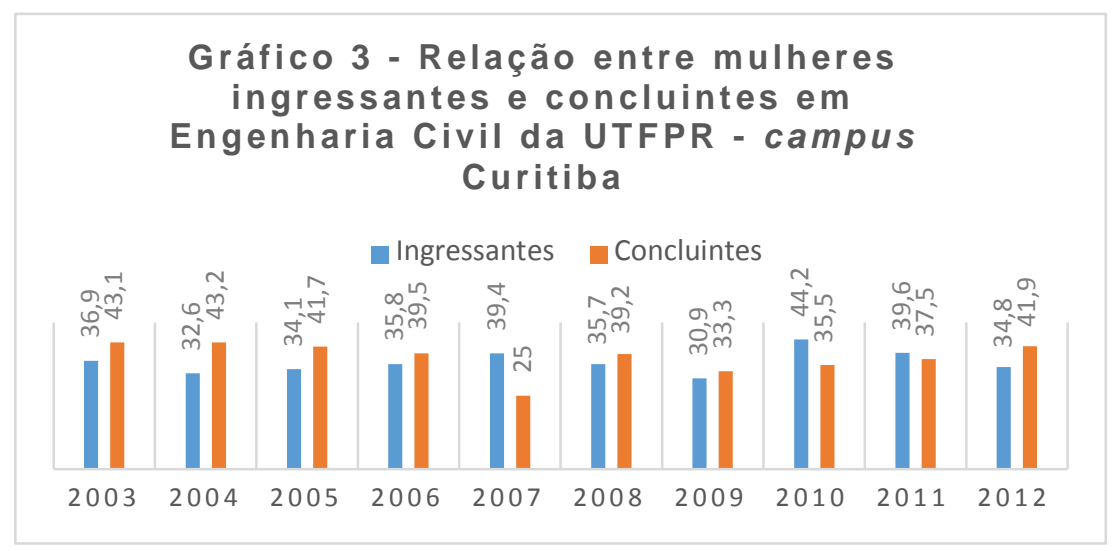

Fonte: Registros da Instituição - Elaboração própria.

Fato semelhante ocorre quando se analisa o mesmo curso na UFBA (GRÁFICO 4) porém fica evidente que a participação feminina das curitibanas neste curso é em torno de 10 pontos percentuais superior a participação das soteropolitanas. Ou seja, se é difícil para as paranaenses ingressarem e se manterem no curso de engenharia, é ainda mais difícil para as baianas. 


\section{Gráfico 4 - Relação entre mulheres \\ ingressantes e concluintes em Engenharia Civil da UFBA}

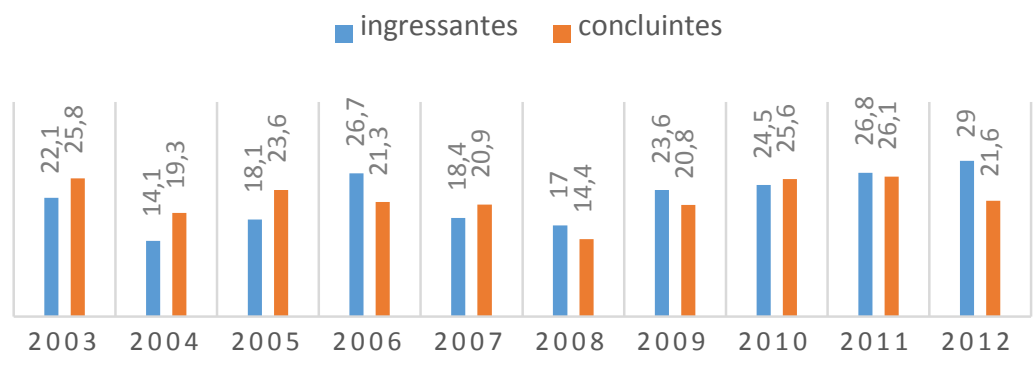

Fonte: Registros da Instituição - Elaboração própria.

Os dados até aqui apresentados indicam que na UTFPR e na UFBA acontece um fenômeno similar ao que acontece nas demais universidade do país. As mulheres são a minoria na maioria das engenharias ofertadas pelas instituições. Demostra a necessidade de se desenvolver ações para que a distribuição de homens e mulheres nestes cursos seja mais equilibrada e deste modo todos, tanto homens quanto mulheres sejam beneficiados com a maior interação no ambiente estudantil e por consequência esta interação no mercado de trabalho seja mais tranquila e vista como "normal".

\section{AS LICENCIATURAS SOB A PERSPECTIVA DE GÊNERO}

As licenciaturas da UTFPR não apresentam trajetória tão tradicional quanto as engenharias. Sua ampliação se deu após a transformação do CEFET-PR em UTFPR ocorrida em 2005. Antes disso, somente o campus Pato Branco oferecia licenciatura em Matemática. Nos dias atuais a Universidade oferece 14 cursos de licenciatura distribuídos em 6 áreas e 10 campi. A maior incidência é a licenciatura em Química com cinco campi e Matemática ofertada em 4 campi. Dois campi não oferecem nenhum curso de licenciatura.

QUADRO 4 - Licenciaturas da UTFPR distribuídas por campus.

\begin{tabular}{|ll|}
\hline Licenciaturas & Número de campus \\
\hline Ciências Biológicas & 1 \\
Física & 1 \\
Informática & 1 \\
Letras & 2 \\
Matemática & 4 \\
Química & 5 \\
Total & 14
\end{tabular}

Fonte: Registros da Instituição - Elaboração própria.

No que tange a presença feminina e masculina nos cursos de licenciatura as mulheres são maioria em quase todos os campi. A exceção é Francisco Beltrão onde a porcentagem de homens é de 73,9\%. Cabe ressaltar que a única licenciatura deste campus é em Informática, campo no qual os homens são a maioria na graduação. A maior incidência feminina está no campus dois vizinhos $(75,2 \%)$ que oferece somente Ciências Biológicas, seguido por Pato Branco (73,3\%) no qual são ofertadas as licenciaturas em Letras, Matemática e Química. 
Observa-se que mesmo nas licenciaturas, as áreas abrangidas pela UTFPR estão vinculadas às ciências "canônicas" com predominância de Química, Matemática e Física. A exceção é Letras que é ofertada em 2 campi (Curitiba e Pato Branco) e pertence a área de humanas. Ou seja, mesmo adentrando nesta área de formação, mesmo buscando a formação docente, a UTFPR não se distancia de suas características primordiais que é a educação tecnológica.

Quando comparamos a capital com o interior percebemos que os números se diferenciam, porém esta diferença não é tão significativa. A capital apresenta $55,2 \%$ de matriculas femininas e o interior elas perfazem $62 \%$ das matrículas. No total das licenciaturas da UTFPR a presença feminina corresponde a $60 \%$ das matrículas.

QUADRO 5 - Estudantes matriculados/as em Licenciaturas por campus e por sexo.

\begin{tabular}{|c|c|c|c|c|c|c|}
\hline \multirow{3}{*}{ Campus da UTFPR } & \multicolumn{6}{|c|}{ Licenciaturas } \\
\hline & \multicolumn{2}{|c|}{ Homens } & \multicolumn{2}{|c|}{ Mulheres } & \multicolumn{2}{|c|}{ Total } \\
\hline & $\mathrm{n}$ & $\%$ & $\mathrm{n}$ & $\%$ & $\mathrm{n}$ & $\%$ \\
\hline Apucarana & 39 & 31,2 & 86 & 68,8 & 125 & 100 \\
\hline Curitiba & 201 & 44,8 & 248 & 55,2 & 449 & 100 \\
\hline Campo Mourão & 39 & 38,2 & 63 & 61,8 & 102 & 100 \\
\hline Cornélio Procópio & 57 & 43,2 & 75 & 56,8 & 132 & 100 \\
\hline Dois Vizinhos & 26 & 24,8 & 79 & 75,2 & 105 & 100 \\
\hline Francisco Beltrão & 51 & 73,9 & 18 & 26,1 & 69 & 100 \\
\hline Guarapuava & 0 & 0 & 0 & 0 & 0 & 0 \\
\hline Londrina & 58 & 50,9 & 56 & 49,1 & 114 & 100 \\
\hline Medianeira & 16 & 32 & 34 & 68 & 50 & 100 \\
\hline Pato Branco & 88 & 26,7 & 241 & 73,3 & 329 & 100 \\
\hline Ponta Grossa & 0 & 0 & 0 & 0 & 0 & 0 \\
\hline Toledo & 40 & 41,7 & 56 & 58,3 & 96 & 100 \\
\hline Total capital & 201 & 44,8 & 248 & 55,2 & 449 & 100 \\
\hline Total interior & 414 & 38 & 674 & 62 & 1088 & 100 \\
\hline Total geral & 615 & 40 & 922 & 60 & 1537 & 100 \\
\hline
\end{tabular}

Fonte: Registros da Instituição. Elaboração própria.

Legenda: $\mathrm{n}$ - número absoluto \%-porcentagem sobre o total de estudantes do campus.

Voltando o olhar para as licenciaturas que são objeto desta pesquisa, Matemática e Letras observamos que na UTFPR a Licenciatura em Matemática, que é ofertada em 4 campi desta universidade, se mostra um curso predominantemente feminino com exceção do campus Curitiba. Observa-se que no campus Pato Branco as mulheres correspondem a $67,5 \%$ das/os matriculadas/as no ano de 2013. Com base nestes dados podemos inferir que as mulheres paranaenses são afeitas a este curso, porém não afirmar com absoluta certeza pois este estudo é localizado em uma única universidade. 
QUADRO 6 - Estudantes matriculados/as na Licenciatura em Matemática por campus e por sexo.

\begin{tabular}{|c|c|c|c|c|c|c|}
\hline \multirow[t]{2}{*}{ Campus } & \multicolumn{2}{|c|}{$\mathbf{F}$} & \multicolumn{2}{|c|}{ M } & \multicolumn{2}{|c|}{$\mathrm{T}$} \\
\hline & $\mathrm{n}$ & $\%$ & $\mathrm{n}$ & $\%$ & $\mathrm{n}$ & $\%$ \\
\hline Cornélio Procópio & 75 & 56,8 & 57 & 43,2 & 132 & 100 \\
\hline Curitiba & 39 & 44,8 & 48 & 55,2 & 87 & 100 \\
\hline Pato Branco & 54 & 67,5 & 26 & 32,5 & 80 & 100 \\
\hline Toledo & 56 & 58,3 & 40 & 41,7 & 96 & 100 \\
\hline Total & 224 & 56,7 & 171 & 43,3 & 395 & 100 \\
\hline
\end{tabular}

Fonte: Registros da Instituição. Elaboração própria.

Legenda: $\mathrm{M}$ - sexo masculino $\mathrm{F}$-Sexo feminino $\mathrm{T}$-total $\mathrm{n}$-número absoluto

$\%$ - porcentagem sobre o total de estudantes do campus.

As mulheres estão mais presentes nesses cursos e este fato pode ser explicado quando se pensa que é "natural" uma mulher se dedicar ao magistério, mesmo que seja nas disciplinas conhecidas como "duras" como a Matemática, a Física e a Química. A adaptação a função de ensinar, de cuidar, supera a suposta inadaptação ao conteúdo da disciplina.

No que se refere a Licenciatura em Letras, a oferta ocorre em apenas dois campi. Podemos perceber que as mulheres são a maioria das/os matriculadas/os no ano de 2013, em ambos. Este curso também se mostra um reduto feminino com o campus do interior apresentando números superiores aos encontrados na capital.

Lembramos que as licenciaturas são recentes na história da UTFPR, sendo assim, os dois cursos aqui analisados ainda não completaram uma década de funcionamento no campus Curitiba, sendo que a licenciatura em Matemática ainda não teve nenhum/a formando/a. Ou seja, a análise fica limitada.

QUADRO 7 - Estudantes matriculados/as na Licenciatura em Letras por campus e por sexo.

\begin{tabular}{|lccccccc|}
\hline Campus & \multicolumn{3}{c}{$\mathbf{F}$} & \multicolumn{3}{c}{$\mathbf{M}$} & \multicolumn{2}{c|}{ T } \\
& $\mathrm{n}$ & $\%$ & $\mathrm{n}$ & $\%$ & $\mathrm{n}$ & $\%$ \\
\hline Curitiba & 162 & 68,6 & 74 & 31,4 & 236 & 100 \\
Pato Branco & 173 & 75,9 & 55 & 24,1 & 228 & 100 \\
Total & 335 & 72,2 & 129 & 27,8 & 464 & 100
\end{tabular}

Fonte: Registros da Instituição. Elaboração própria.

Legenda: $\mathrm{M}$ - sexo masculino $\mathrm{F}$-Sexo feminino $\mathrm{T}$-total $\mathrm{n}$ - número absoluto $\%$ - porcentagem sobre o total de estudantes do campus.

No QUADRO 8 apresentamos os números relativos aos/às ingressantes no período de 2008 a 2013, ou seja, durante toda a história destes cursos na Instituição. Percebemos que as mulheres são a maioria na Licenciatura em Letras sendo que a maior incidência aconteceu no ano de 2013 com 73,8\% do total de ingressantes e o menor índice encontramos no ano de 2009 no qual as mulheres corresponderam a $57,8 \%$ do total. 
QUADRO 8 - Ingressantes nas Licenciaturas da UTFPR campus Curitiba por ano e por sexo.

\begin{tabular}{|c|c|c|c|c|c|c|c|c|c|c|}
\hline \multirow[t]{3}{*}{ Ano } & \multicolumn{5}{|c|}{ Lic. Letras } & \multicolumn{5}{|c|}{ Lic. Matemática } \\
\hline & \multicolumn{2}{|r|}{$\mathbf{F}$} & \multicolumn{2}{|c|}{ M } & \multirow[t]{2}{*}{$T$} & \multicolumn{2}{|r|}{$\mathbf{F}$} & \multicolumn{2}{|c|}{ M } & \multirow[t]{2}{*}{$\mathbf{T}$} \\
\hline & $\mathrm{n}$ & $\%$ & $\mathrm{n}$ & $\%$ & & $n$ & $\%$ & $\mathrm{n}$ & $\%$ & \\
\hline 2008 & 30 & 63,8 & 17 & 36,2 & 47 & & & & & \\
\hline 2009 & 59 & 57,8 & 43 & 42,2 & 102 & & & & & \\
\hline 2010 & 73 & 70,9 & 30 & 29,1 & 103 & 27 & 52,9 & 24 & 47,1 & 51 \\
\hline 2011 & 77 & 71,3 & 31 & 28,7 & 108 & 37 & 38,9 & 58 & 61,1 & 95 \\
\hline 2012 & 74 & 64,3 & 41 & 35,7 & 115 & 42 & 40,4 & 62 & 59,6 & 104 \\
\hline 2013 & 76 & 73,8 & 27 & 26,2 & 103 & 41 & 40,6 & 60 & 59,4 & 101 \\
\hline
\end{tabular}

Legenda: $\mathrm{M}$ - sexo masculino $\mathrm{F}$-Sexo feminino $\mathrm{T}$-total $\mathrm{n}$ - número absoluto $\%$ - porcentagem sobre o total de estudantes do campus.

No que diz respeito a Licenciatura em Matemática do campus Curitiba observa-se que os homens são a maioria dos ingressantes em 3 dos 4 anos analisados. Apenas no primeiro ano de oferta do curso a porcentagem de mulheres superou a de homens, porém podemos observar que a diferença é menor do que no caso da Licenciatura em Letras. No que se refere aos/às concluintes tivemos apenas duas turmas de formandos/as na licenciatura em Letras e nenhuma em Matemática. Podemos observar que as mulheres são a maioria dentre as/os concluintes (94\% em 2012 e 77,8\% em 2013).

Quando se observa aos números relativos aos estudantes das duas licenciaturas objeto desta pesquisa, Letras Vernáculas e Matemática da UFBA temos quadros semelhantes aos encontrados na UTFPR campus Curitiba, porém com números distintos. Letras é um curso com predominância feminina nas duas universidades porém esta predominância é maior na UFBA e Matemática apresenta predominância masculina em ambas as instituições e, novamente mais acentuada na UFBA. A Licenciatura é ofertada há mais tempo na UFBA e desta forma temos números mais consolidados no que se refere ao ingresso e conclusão do curso por parte dos homens e das mulheres.

QUADRO 9 - Ingressantes nas Licenciaturas da UFBA por ano e por sexo.

\begin{tabular}{|c|c|c|c|c|c|c|c|c|c|c|}
\hline \multirow[t]{3}{*}{ Ano } & \multicolumn{5}{|c|}{ Lic. Letras Vernáculas } & \multicolumn{5}{|c|}{ Lic. Matemática } \\
\hline & \multirow{2}{*}{\multicolumn{2}{|c|}{$=$}} & \multicolumn{2}{|c|}{$\mathrm{M}$} & \multirow[t]{2}{*}{$\mathrm{T}$} & \multicolumn{2}{|c|}{$\mathrm{F}$} & \multicolumn{2}{|c|}{$\mathrm{M}$} & \multirow{2}{*}{ T } \\
\hline & & & $\mathrm{n}$ & $\%$ & & $\mathrm{n}$ & $\%$ & $\mathrm{n}$ & $\%$ & \\
\hline 2003 & 173 & 78,3 & 48 & 21,7 & 221 & 24 & 32 & 51 & 68 & 75 \\
\hline 2004 & 148 & 76,3 & 46 & 23,7 & 194 & 20 & 25 & 60 & 75 & 80 \\
\hline 2005 & 186 & 74,7 & 63 & 25,3 & 249 & 127 & 58,2 & 91 & 41,8 & 218 \\
\hline 2006 & 172 & 82,7 & 36 & 17,3 & 208 & 25 & 32,5 & 52 & 67,5 & 77 \\
\hline 2007 & 122 & 62,9 & 72 & 37,1 & 194 & 17 & 23,9 & 54 & 76,1 & 71 \\
\hline 2008 & 131 & 71,2 & 53 & 28,8 & 184 & 22 & 25 & 66 & 75 & 88 \\
\hline 2009 & 196 & 76 & 62 & 24 & 258 & 30 & 26,3 & 84 & 73,7 & 114 \\
\hline 2010 & 205 & 73,7 & 73 & 26,3 & 278 & 30 & 25,9 & 86 & 74,1 & 116 \\
\hline 2011 & 185 & 68,5 & 75 & 27,8 & 270 & 38 & 29,9 & 89 & 70,1 & 127 \\
\hline 2012 & 161 & 66,5 & 81 & 33,5 & 242 & 13 & 25,5 & 38 & 74,5 & 51 \\
\hline
\end{tabular}

Fonte: Departamento de Estatística da UFBA. Elaboração própria. $\%$ - porcentagem sobre o total de estudantes do campus. 
No que diz respeito aos concluintes, podemos perceber que as mulheres se mantem a maioria em Letras Vernáculas e os homens a maioria em Matemática. Porém, ao compararmos os QUADROS 9 e 10 podemos perceber que a porcentagem de mulheres que se formam em Matemática é superior à das que ingressam. As taxas de ingressantes giram na faixa de $25 \%$ a $35 \%$ com exceção do ano de 2005 onde as mulheres corresponderam a 58,2\% dos/as matriculados/as. Quando analisamos as concluintes vemos que a faixa se amplia e gira entre $25 \%$ e 47\% com um pico em 2012 onde elas corresponderam a 50,8\% do total de formandos/as.

Com base nestes números podemos concluir que as mulheres que ingressam em licenciatura e Matemática são mais propensas a concluir o curso. Este fato não necessariamente se apresenta como positivo. Faz-se necessário a realização de pesquisas para identificar as razões que levam os estudantes, homens e mulheres a desistir do curso.

QUADRO 10 - Concluintes nas Licenciaturas da UFBA por ano e por sexo.

\begin{tabular}{|c|c|c|c|c|c|c|c|c|c|c|}
\hline \multirow[t]{3}{*}{ Ano } & \multicolumn{5}{|c|}{ Lic. Letras Vernáculas } & \multicolumn{5}{|c|}{ Lic. Matemática } \\
\hline & \multicolumn{2}{|r|}{$=$} & \multirow{2}{*}{\multicolumn{2}{|c|}{$\frac{M}{n} \frac{M}{\%}$}} & \multirow[t]{2}{*}{$\mathrm{T}$} & \multicolumn{2}{|r|}{$\mathrm{F}$} & \multicolumn{2}{|c|}{$\mathrm{M}$} & \multirow[t]{2}{*}{$\mathrm{T}$} \\
\hline & $\mathrm{n}$ & $\%$ & & & & $n$ & $\%$ & $n$ & $\%$ & \\
\hline 2003 & 116 & 78,9 & 31 & 21,1 & 147 & 9 & 39,1 & 14 & 60,4 & 23 \\
\hline 2004 & 33 & 67,3 & 16 & 32,6 & 49 & 9 & 47,4 & 10 & 52,6 & 19 \\
\hline 2005 & 114 & 85,1 & 20 & 14,9 & 134 & 10 & 38,5 & 16 & 61,4 & 26 \\
\hline 2006 & 95 & 75,4 & 31 & 24,6 & 126 & 9 & 45 & 11 & 55 & 20 \\
\hline 2007 & 95 & 79,8 & 24 & 20,2 & 119 & 7 & 25,9 & 20 & 74,1 & 27 \\
\hline 2008 & 104 & 78,2 & 29 & 21,8 & 133 & 12 & 35,3 & 22 & 64,7 & 34 \\
\hline 2009 & 118 & 77,6 & 34 & 22,4 & 152 & 11 & 32,4 & 23 & 67,6 & 34 \\
\hline 2010 & 118 & 78,7 & 32 & 21,3 & 150 & 6 & 25 & 18 & 75 & 24 \\
\hline 2011 & 104 & 71,7 & 41 & 28,3 & 145 & 9 & 33 & 18 & 67 & 27 \\
\hline 2012 & 101 & 74,8 & 34 & 25,2 & 135 & 32 & 50,8 & 31 & 49,2 & 63 \\
\hline
\end{tabular}

Fonte: Departamento de Estatística da UFBA. Elaboração própria

Legenda: $\mathrm{M}$ - sexo masculino $\mathrm{F}$-Sexo feminino $\mathrm{T}$ - total $\mathrm{n}$ - número absoluto $\%$ - porcentagem sobre o total de estudantes do campus.

\section{CONSIDERAÇÕES FINAIS}

Os dados levantados por esta pesquisa demonstram que a realidade da UTFPR campus Curitiba e da UFBA convergem para os números relacionados a educação superior no Brasil que apontam as engenharias como espaços dominados pelos homens. No caso da UTFPR campus Curitiba estes dados também reforçam a trajetória histórica da Instituição que desde a sua fundação tinha como público alvo os meninos "órfãos e desvalidos da sorte". O histórico de sua fundação permanece quase que intocado no quadro discente da instituição, porém as mulheres, gradativamente, têm assumido um papel relevante dentro da instituição de modo especial nas licenciaturas e na Engenharia Civil.

Analisando os dados quantitativos das duas universidades podemos encontrar mais similaridades do que contrastes. Destacamos que as duas instituições se localizam em regiões com culturas distintas. Enquanto a UTFPR campus Curitiba está localizada na região sul do Brasil, região esta colonizada por descendentes de europeus, a UFBA está sediada em Salvador no nordeste 
brasileiro e tem grande influência da cultura africana. Esta diferença cultural parece pouco interferir nos números relativos a presença feminina e masculina nas engenharias e licenciaturas.

Com base na análise dos dados aqui apresentados podemos concluir que a Licenciatura em Letras se mostra mais acessível e interessante às mulheres do que a Licenciatura em Matemática. E a Engenharia Civil atrai mais mulheres do que a Engenharia Mecânica.

As razões destes números podem ser diversas. Para conhecermos os motivos que resultam nos dados aqui apresentados torna-se necessária a realização de pesquisas de cunho qualitativo com o corpo docente e discente, buscando identificar diversas razões que levam eles e elas a escolherem os cursos nos quais estão matriculados bem como as dificuldades e facilidades de permanência nestes cursos. Uma contribuição a estes estudos será dada pela continuação desta pesquisa que terá cunho qualitativo e que encontra-se em andamento. 


\title{
CONTRASTS AND SIMILARITIES: a gender perspective on UTFPR and UFBA Engineering and Licensing Courses
}

\begin{abstract}
The purpose of this article is to present data on male and female participation in the courses of Civil and Mechanical Engineering and Degree in Letters and Mathematics of UTFPR and UFBA. For this study, we will use the quantitative method based on information obtained from both institutions. The results presented here are part of the first phase of the research for the post-doctorate stage in the Graduate Program in Studies on Women, Gender and Feminism - PPGNEIM, Federal University of Bahia - UFBA, whose objective is to analyze engineering And UTFPR and UFBA degrees from a gender perspective. The study consists of two stages: the first, quantitative, aims to build the panorama of this participation in these courses and has the results presented here. The second stage, with a qualitative approach, seeks to know the reasons why men and women choose one or another course, as well as the difficulties and facilities faced by them and them to remain in the chosen courses, considering their respective sociocultural contexts. The data show that women are the minority in Engineering, especially in Mechanical Engineering where numbers rarely reach $15 \%$. As far as the degrees are concerned, they are absolute majority in Letters, but in Mathematics the numbers oscillate a lot and are close. It is important to note that regional and / or cultural differences do not seem to change the unequal distribution of men and women in the courses analyzed, in two contrasting institutions in many respects. The results presented here indicate the relevance of the second stage of the research.
\end{abstract}

KEYWORDS: Gender Relations. Engineering. Licenciaturas. UTFPR. UFBA. 
1 Trabalho Apresentado no X Congreso Iberoamericano de Género, Ciencia y Tecnologia realizado em 2014 em assunção - Paraguay.

2 A Medalha Fields é vista como a maior honraria que um matemático pode receber. É também conhecida como Medalha Internacional de Descobrimentos Proeminentes em Matemática, e concedida na ocasião da realização do Congresso Internacional da União Internacional de Matemática (IMU) que ocorre a cada 4 anos e premia dois, três ou quatro matemáticos com não mais de 40 anos de idade.

3 A Instituição tem atualmente 13 campi porém em um deles, Santa Izabel, ainda não tem cursos em funcionamento pois o mesmo foi recém criado.

4 Neste estudo estamos agrupando os dois cursos pela similaridade. Em Curitiba, por exemplo, o curso de engenharia Industrial Mecânica está sendo extinto e sendo substituído pelo de Mecânica.

5 Agruparemos os dois cursos por terem grades semelhantes e mercado de trabalho também similar.

\section{REFERÊNCIAS}

CABRAL, Carla Giovana; BAZZO,Walter Antonio. (2005) As mulheres nas escolas de engenharia brasileiras: história, educação e futuro. Revista de Ensino de Engenharia, v. 24, n. 1, p. 3-9.

CARVALHO, Marilia Gomes de. (2008) É possível transformar a minoria em eqüidade?. In: RISTOFF, Dilvo; GROZ, Dirce Margarete; CABRAL, Maria das Graças Serafim; LEPORACE, Maria Marcia dos Santos; LOPES, Maria Margaret; MIGUEL, Sonia Malheiros. (Orgs.). Simposio "Gênero e indicadores da educação superior brasileira". 1 ed. Brasilia: INEP, v. 1, p. 109-138.

CASAGRANDE, Lindamir Salete et. al.(2004) Mulher e ciência: pioneiras em ciência da natureza. Cadernos de artigos sobre Gênero e Tecnologia, no 1, v. 1, Curitiba, p. 3-14.

CASAGRANDE, Lindamir Salete; CARVALHO M. G., Marilia Gomes de. (2008) Profissão professora: a carreira do magistério no Paraná sob a ótica de gênero. In: Fazendo Gênero 8: corpo, violência e poder. Florianópolis, SC. Anais... Florianópolis, Editora Mulheres, 2009. Disponível em http://www.fazendogenero8.ufsc.br/sts/ST38/Casagrande-Carvalho_38.pdf, Acessado em 18 de janeiro de 2010.

CASAGRANDE, Lindamir Salete; CARVALHO, Marilia Gomes. (2011) Desempenho escolar em Matemática: o que o gênero tem a ver com isso? In: CASAGRANDE, Lindamir Salete; LUZ, Nanci Stancki da., CARVALHO, Marilia Gomes de. (Orgs) 
Igualdade de Gênero: enfrentando o sexismo e a homofobia. Curitiba: Editora UTFPR.

COSTA, Claudia de Lima. (1994) O leito de procusto. Cadernos Pagu, Campinas, p. 141-174.

FELIPE, Jane; GUIZZO, Bianca Salazar. (2003). Erotização dos corpos infantis na sociedade de consumo. Pro-Posições, Campinas, v. 14, n. 3 (42), p. 121-130.

GONZÁLEZ GARCÍA, Marta I.; PÉREZ SEDEÑO, Eulalia. (2006) Ciencia, Tecnología y Género. In: SANTOS, Lucy Woellner dos; ICHIKAWA, Elisa Yoshie; CARGANO, Doralice de Fátima. Ciência, Tecnologia e Gênero: desvelando o feminino na construção do conhecimento. Londrina: IAPAR, p. 33-72.

LOMBARDI, Maria Rosa. (2006) Engenheiras brasileiras: inserção e limites de gênero no campo profissional. Cadernos de Pesquisa (Fundação Carlos Chagas), Campinas, São Paulo: v. 36, p. 173-202.

SCHIEBINGER, Londa. (2001) O feminismo mudou a ciência? Trad. Raul Fiker. Bauru-SP: EDUSC.

SCOTT, Joan. (1995) Gênero: Uma categoria útil de análise histórica. Educação \& Realidade, Porto Alegre, v. 20, n. 2, p. 71-99.

SELKE, Stefan. (2006) A complexidade da identidade inconsciente de gêneroresultado de uma pesquisa entre os estudantes da Fachhochschule Furtwangen. Tecnologia e Sociedade, Curitiba, n. 3, p. 137-174.

SIMIÃO, Daniel Schroeter (2005). Gênero no mundo do trabalho: variações sobre um tema. Cadernos de Gênero e Tecnologia, v. 5, ano 2, p. 9-20.

TERRA (2014). Iraniana é a primeira mulher a ganhar 'Nobel' da Matemática. Disponível em http://noticias.terra.com.br/ciencia/pesquisa/iraniana-e-aprimeira-mulher-a-ganhar-nobel-damatematica,96a305f462cc7410VgnVCM3000009af154d0RCRD.html. Acessado em 29/08/2014.

VELHO, Lea. Apresentação. In: SANTOS, Lucy Woellner dos; ICHIKAWA, Elisa Yoshie; CARGANO, Doralice de Fátima.(2006) Ciência, Tecnologia e Gênero: desvelando o feminino na construção do conhecimento. Londrina: IAPAR, p. 9-18. 
Recebido: 10 de setembro de 2016

Aprovado: 29 de outubro de 2016.

Como citar:

CASAGRANDE, Lindamir S.; FAGUNDES, LIMA E SOUZA, Â. M. F.. Contrastes e similaridades: um olhar de gênero sobre cursos de engenharias e licenciaturas da UTFPR e da UFBA. Cad. Gên. Tecnol., Curitiba, v.9, n. 34, p. 41-57, jul./dez. 2016.

Correspondência:

Lindamir Salete Casagrande

Rua Eurides Cunha, 85, apto. 1325. 80320010, Curitiba.

Direito autoral: Este artigo está licenciado sob os termos da Licença Creative Commons Atribuição 4.0 Internacional.

(c) (i) 